\title{
História de vida na pesquisa com adultos com deficiência: algumas reflexões
}

\author{
Rogério Drago \\ Universidade Federal do Espírito Santo, Espirito Santo- ES, Brasil. \\ rogerio.drago@gmail.com \\ Camila Reis dos Santos \\ Universidade Federal do Espírito Santo, Espirito Santo- ES, Brasil. \\ camiletsreis@yahoo.com.br
}

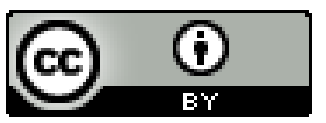

Educação: teoria e prática, Rio Claro, SP, Brasil - elSSN: 1981-8106

Está licenciada sob Licença Creative Common

\section{Resumo}

Entendendo que o ser humano produz história e cultura ao mesmo tempo em que é invadido pela história e pela cultura dos outros seres com os quais entra em contato durante toda a sua vida, este texto busca discutir a metodologia de história de vida para a pesquisa com adultos que possuem deficiência, transtornos globais do desenvolvimento ou altas habilidades/superdotação, reconhecendo-os como sujeitos que possuem voz e que, a partir de suas narrativas, podem contribuir para que suas subjetividades e identidades sejam reconhecidas. Nesse sentido, trata-se de um estudo teórico onde são apresentadas as características do método de história de vida, sua importância para a pesquisa educacional, seus procedimentos, bem como seu valor no resgate da identidade e subjetividade de pessoas adultas com deficiência, transtornos globais do desenvolvimento ou altas habilidades/superdotação.

Palavras-chave: História de vida. Pesquisa educacional. Adultos com deficiência.

\section{Life history research with adults with disabilities: some reflections}

\author{
Abstract \\ Understanding that the human being produces history and culture at the same time it is \\ invaded by history and culture of other beings with which it comes in contact throughout \\ their lives, this text discusses the methodology of life history for research adults who have \\ disabilities, pervasive developmental disorders or high skills giftedness, acknowledging them
}


as individuals who have a voice and from their narratives, can contribute to their subjectivities and identities are recognized. In this sense, it is a theoretical study which shows the characteristics of the method of life history, its importance for educational research, its procedures and its value in the rescue of the identity and subjectivity of adults with disabilities, disorders global development or high abilities / giftedness.

Keywords: History of life. Educational research. Adults with disabilities.

\section{Introdução}

Os estudos referentes às vidas [...] podem ajudar-nos a ver o indivíduo em relação com a história de seu tempo, permitindo-nos encarar a intersecção da história de vida com a história da sociedade, esclarecendo, assim, as escolhas, contingências e opções que se deparam ao indivíduo (GOODSON, 1992)

Neste texto pretendemos discutir o papel das histórias de vida enquanto método que permite recolha de dados e informações de um grupo específico de pessoas - adultos com deficiência, transtornos globais do desenvolvimento ou altas habilidades/superdotação que poderão ser muito pertinentes na investigação educacional, no sentido de reconhecer tais sujeitos como produtores de histórias que podem culminar em novas/outras possibilidades de ressignificar a ação educacional a partir da fala de sujeitos que vivem/viveram a deficiência.

A escolha por discutir tal proposta metodológica com sujeitos adultos se dá por alguns motivos, quais sejam: a escassez de pesquisas que resgatem a fala desses indivíduos a partir de suas próprias vivências (SANTOS, 2013) e pelo fato de que essas pessoas talvez possuam uma história de vida marcada por uma série de eventos/experiências sociais, históricos e culturais de inclusão e de exclusão muito maior do que crianças e/ou adolescentes, que são negligenciadas e podem nos dar pistas interessantes de como pensar novas/outras possibilidades de ações políticas e educacionais.

Em se tratando, portanto, de um ensaio teórico, este texto abarca uma breve discussão teórica acerca da Metodologia de História de Vida como proposta de pesquisa, e a entrevista dialógica semiestruturada como procedimento, para, em seguida, apresentarmos a importância de se resgatar/registrar/ouvir a voz de sujeitos adultos com deficiência, transtornos globais do desenvolvimento ou altas habilidades/superdotação. Ressaltamos, ainda, que a preocupação em trazer o método de história de vida como proposta para a pesquisa com sujeitos adultos com deficiência surgiu por entendermos que esses indivíduos 
possuem uma história que precisa ser contada, ouvida, registrada, para que não percamos subjetividades tão ímpares que podem trazer uma contribuição muito grande para pensarmos ações educativas numa perspectiva inclusiva.

\section{História de Vida: para uma caracterização}

O método de História de Vida é um método cientifico com toda força, validade e credibilidade de qualquer outro método, sobretudo porque revela que por mais individual que seja uma história, ela é sempre, ainda, coletiva, mostrando também o quão genérica é a trajetória do ser humano (SILVA et al, 2007, p. 34).

A ciência firmou-se como um campo de conhecimento sólido ao tentar entender o mundo através de uma sistematização e uma acumulação do conhecimento produzido sobre os fenômenos (SILVA et al, 2007). A influência exercida pelos métodos experimentais das ciências físicas e biológicas, na história das ciências humanas, é evidente.

Entendemos que a ciência é historicamente construída e não se sobrepõe aos outros campos de conhecimento, como a religião e a arte, esferas igualmente úteis para compreender o homem em sua complexidade. No século XX, a neutralidade e a objetividade guiavam a ciência, mas, hoje, o que se vê é o reconhecimento da impossibilidade dessa neutralidade, na mesma medida em que o compromisso com a sociedade vai sendo reafirmado e suas estratégias reinventadas e estabelecidas (SILVA et al, 2007). É nesse âmbito que surge o interesse pelos estudos qualitativos, como um movimento de ruptura que se iniciou no século XX. As mudanças trazidas pela ruptura da ciência essencialmente quantitativa se referem, segundo Bueno (2002), não somente à busca de novos métodos de investigação, mas, sobretudo, a um modo novo de conceber a própria ciência.

O momento favorece uma nova síntese que evite todas as formas de reducionismo e reificação, sejam eles econômicos, linguísticos ou culturais, uma síntese que não perca de vista a articulação entre microfísica e macro-física do poder que reconhece que a subjetividade é ao mesmo tempo constituída e constituinte uma síntese enfim que seja centrada na teoria da práxis enriquecida pelas novas experiências e que leve a uma nova historiografia e uma nova estratégia que permita coordenar os vários movimentos sociais sem retirar-lhes a autonomia, e que a partir de uma reflexão sobre o passado e o presente prepare os caminhos do futuro (BUENO, 2002, p. 16).

A pesquisa qualitativa preocupa-se com os indivíduos e seus ambientes em suas complexidades, não havendo limites ou controle impostos pelo pesquisador (SPINDOLA; SANTOS, 2003). Nesse sentido, uma característica importante da metodologia qualitativa é a relação entre sujeito pesquisador e sujeito pesquisado, que, embora perpassada por 
relações de poder, constitui momento de construção, diálogo de um universo de experiências humanas (SILVA et al, 2007).

A contribuição da pesquisa qualitativa estende-se desde as fronteiras da antropologia e da etnografia, passando pela etnometodologia, a hermenêutica, e diversas modalidades de estruturalismo, até as análises históricas comparadas, relatos orais, método biográfico e outras técnicas da história oral ou história de vida (GONÇALVES; LISBOA, 2007).

Emolduradas na metodologia qualitativa, as abordagens biográficas caracterizam-se por um compromisso com a história como processo de rememorar, com o qual a vida vai sendo revisitada pelo sujeito. Nesse contexto, a memória é algo presente na existência do homem, o que implica numa valiosa importância de seu resgate cuidadoso e ético (SILVA et al, 2007).

O método biográfico, que inclui as várias modalidades de estudo com histórias de vida, constitui-se um recurso recente na área das ciências da educação. Foi empregado em larga escala, segundo Bueno (2002), nos anos 1920 e 1930, pelos sociólogos da Escola de Chicago, animados com a busca de alternativas à sociologia positivista. Após esse sucesso o método sofreu um colapso súbito e radical, caindo em quase completo desuso nas décadas seguintes, em razão da preponderância da pesquisa empírica entre os sociólogos americanos.

Após seu declínio, o aporte metodológico de histórias de vida passa a ser novamente utilizado no âmbito da sociologia, por volta dos anos 1980. Alguns aspectos contribuíram para uma crescente valorização do método autobiográfico como, por exemplo, segundo Bueno (2002), o caráter exacerbadamente técnico da metodologia sociológica, fundamentado no axioma da objetividade e na hegemonia da intencionalidade nomotética ${ }^{1}$. De outro lado, o método biográfico corresponde à exigência de uma nova antropologia, devido aos apelos vindos de vários setores para se conhecer melhor a vida cotidiana. Nesse sentido, segundo Bertaux (1981), histórias de vida, por mais particulares que sejam, são sempre relatos de práticas sociais: das formas com que o indivíduo se insere e atua no mundo e no grupo do qual ele faz parte: "Ao relatar situações vividas, o sujeito objetiva-se a

\footnotetext{
${ }^{1} \mathrm{O}$ fundamento da abordagem nomotética está na crença de que o modelo das ciências naturais é pertinente para as ciências sociais e, em sendo assim, estas deveriam aderir à proposição de que as leis gerais que regem os fenômenos do universo são necessárias e constantes. Caberia às ciências sociais, então, descobrir as leis gerais do comportamento e das ações humanas por meio da adoção dos procedimentos metodológicos das ciências naturais.
} 
partir dos outros; são esses outros que fornecem a referência para a maneira de olhar para os eventos narrados" (OLIVEIRA, 2006, p. 255).

Segundo Silva et al (2007), a História de Vida é um método que tem como principal característica, justamente, a preocupação com o vínculo entre pesquisador e sujeito. pesquisador que trabalha com esse tipo de metodologia, ao fazer com que as pessoas confiem nas lembranças e interpretações particulares do passado, em sua capacidade de colaborar para escrever a história, possibilita que os entrevistados, quase sempre ignorados e economicamente fragilizados, adquiram dignidade e sentido de finalidade ao rememorar a própria vida e fornecer informações valiosas (THOMPSON, 1992). Trata-se, portanto, de penetrar nas entranhas e nas entrelinhas das vozes dos sujeitos, captar sentimentos implícitos e sensações escondidas que se tornam visíveis e ganham destaque no processo de narrar, tanto para o pesquisador quanto para o próprio entrevistado.

Há obras que nos mostram a sala de visitas de História, com os retratos emoldurados na parede, os móveis de estilo e um belo arranjo para ser visto. Mas há pesquisas que vão nos fundos da casa, às cozinhas e oficinas, que esgaravatam os terrenos baldios onde se lançam detritos, aqueles lugares onde se movem as figuras menores e furtivas (BOSI, 1984, p. 03).

O objetivo do método da história de vida é ter acesso a uma realidade que ultrapassa o narrador. Isto é, por meio da história de vida contada da maneira que é própria do sujeito, tentamos compreender o universo do qual ele faz parte. Isto nos mostra a faceta do mundo subjetivo em relação permanente e simultânea com os fatos sociais (BARROS; SILVA, 2002).

Alguns autores acatam os termos história de vida e história oral como sinônimos. Em outros casos, existe uma distinção entre os termos metodológicos, que trazemos, agora, especificados.

Segundo Gonçalves; Lisboa (2007), a história de vida é tida como uma modalidade da história oral, definindo-a com um constructo histórico e social que utiliza diferentes técnicas de entrevista para dar voz aos sujeitos até então invisíveis.

O método da história oral utiliza diferentes técnicas de entrevista para dar voz a sujeitos invisíveis e, por meio da singularidade de seus depoimentos, constrói e preserva a memória coletiva. Pesquisadores que trabalham com história oral (LifeCourse-Forschung) na Europa, e mais especificamente na Alemanha, utilizam as terminologias "biografia" e "trajetória de vida" como procedimentos metodológicos dessa abordagem (GONÇALVES; LISBOA, 2007 p. 05, grifos dos autores).

Na visão de Silva et al (2007), contudo, o método de História Oral envolve o estudo do indivíduo na sua singularidade. Esse método levanta a possibilidade de uma maior 
aproximação com a realidade na qual o sujeito está inserido, fazendo uso de uma pesquisa mais direcionada através de interrogatórios. Cabe ressaltar a inexistência, nesse método, da preocupação com o vínculo entre pesquisadores e sujeitos da pesquisa - importante distinção com relação ao método de Historia de Vida.

A História de Vida é um método que tem como principal característica, justamente,
a preocupação com o vínculo entre pesquisador e sujeito. Haguette (1992) sugere
que o método de história de vida, dentro da metodologia de abordagem biográfica,
relaciona duas perspectivas metodológicas intimamente, podendo ser aproveitado
como documento ou como técnica de captação de dados. Acrescentamos, nas duas
perspectivas, a produção de sentido - importante proposta da aplicação deste
método (HAGUETTE, 1992 apud SILVA et al, 2007, p. 05).

Ainda, na visão de Silva et al (2007), dentro do quadro referencial da metodologia qualitativa biográfica, destacam-se: a História Oral, Biografia, Autobiografia e História de Vida, cada qual com seus próprios procedimentos, sendo esses independentes. A referência comum, entre as abordagens que se pretendem biográficas, diz respeito, somente, ao que constitui o núcleo central do método: a dimensão do contar e da narrativa. No mais, o que se observa é uma ausência total de consenso entre as mesmas.

A opção metodológica pela história de vida é compatível com o trabalho de pesquisa com sujeitos adultos com deficiência, transtornos globais do desenvolvimento ou com altas habilidades/superdotação, uma vez que permite penetrar na trajetória de vida dos sujeitos envolvidos, bem como compreender a dinâmica das relações que o indivíduo estabelece/estabeleceu ao longo de sua existência (SPINDOLA; SANTOS, 2003). Além da adequação ao tema, a metodologia de história de vida atende a uma proposta teórica que tem embasado muitos de nossos estudos - a proposta sócio-histórica de Vigotski e colaboradores - uma vez que é histórica, dinâmica e dialética.

[...] através das narrativas de sua vida, o indivíduo se preenche de si mesmo, se obrigando a organizar de modo coerente as lembranças desorganizadas e suas percepções imediatas: esta reflexão do si faz emergir em sua narração todos os microeventos que pontuam a vida cotidiana, do mesmo modo que as durações, provavelmente comuns aos grupos sociais, mas que dentro da experiência individual contribuem para a construção social da realidade (CIPRIANI et al, 1983, apud SPINDOLA; SANTOS, 2003, p. 04).

No que tange aos procedimentos de coleta de dados nessa proposta metodológica, acreditamos, segundo Freitas (2002), que a entrevista na pesquisa qualitativa é marcada pela dimensão social. Ela não se reduz a uma troca de perguntas e respostas, previamente preparadas, mas é concebida como uma produção de linguagem, portanto, dialógica. 
Não se busca na entrevista uniformidade absoluta, nem padronização dos relatos, mas a riqueza que cada entrevistado tem a contar - riqueza que não se traduz na extensão das falas, mas às vezes na citação de um fato desconhecido, na descrição de um fato corriqueiro (DEMARTINI, 1992 apud CASSAB; RUSCHEINSKY, 2004, p. 15).

Isso posto, entendemos que a entrevista semiestruturada biográfica se adéqua à referida perspectiva metodológica, uma vez que é tomada no sentido dialógico, visando mais a construção e a reconstrução dos sentidos do que a aplicação de perguntas. Rompe com uma pretensa cientificidade que buscaria respostas exatas para indagações diretas, ultrapassa tanto uma abordagem generalista, teoricista, que se satisfaz com abstrações descoladas do real, quanto uma abordagem empiricista, colada no real, dependente da coisa vista, retratada, presa a ela, fotografada (KRAMER; SOUZA, 2008).

A entrevista biográfica se constitui a partir de uma relação dialógica entre dois ou mais locutores que compreende tensões, expectativas, sanções, proibições, conflitos, hierarquias de poder, confronto de normas e valores implícitos ou explícitos (KRAMER; SOUZA, 2008, p. 28).

A entrevista, dentro da modalidade de história de vida, é, segundo Le Ven; Faria; Motta (1997, p. 215):

[...] um momento solene, uma vez que o entrevistado concorda em desnudar sua história diante de pessoas normalmente desconhecidas - o que não é uma situação comum. Este momento da entrevista traz ainda à tona, reflexões por parte do entrevistado, o que o permite, e em certa medida o impulsiona, a tecer sua rede de relações e experiências do vivido.

Transitando entre a entrevista no método de história de vida e a perspectiva sóciohistórica pode-se afirmar que

[...] Em análises de história de vida, pode se perceber as nuances da sociedade ou de um grupo específico de pessoas, pois o indivíduo, inserido num contexto, reflete as características deste. $E$ é, a priori, exatamente este o nosso interesse: a relação entre o individual e o coletivo [...] (LE VEN; FARIA; MOTTA, 1997, p. 216).

Tem-se, portanto, que a entrevista na modalidade de história de vida é capaz de captar, segundo Queiroz (1991 apud LE VEN; FARIA; MOTTA, 1997, p. 216): “o que sucede na encruzilhada da vida individual com o social". O ouvir no instante da entrevista torna possível, ainda, um reconhecimento e respeito recíprocos entre entrevistado e entrevistador, pessoas que estão continuamente crescendo como seres humanos, como mulheres e homens que sabem do sentido de certos atos humanos.

Ainda, tecendo redes entre a opção procedimental de coleta de dados e o entendimento do sujeito como um ser que produz história e cultura dialeticamente, 
independente de características físicas, mentais ou sensoriais, e partindo da ideia de que a linguagem é organizadora do pensamento, e a palavra se apresenta como fundamento da vida interior do sujeito, as narrativas das entrevistas têm um papel essencial na organização das funções psicológicas superiores e no reconhecimento da alteridade desse sujeito, uma vez que

[...] a narrativa é um modo de pensamento, pois ela se apresenta como princípio organizador da experiência humana no mundo social, do seu conhecimento sobre ele e das trocas que ele mantém [...] a narrativa é a ferramenta mais importante para a construção do significado em nossa cultura, sendo assim a narrativa é um tipo de pensamento que sempre expressa um saber (BRUNER, 1997 apud VAZ; MENDES; MAUÉS, 2001, p. 04).

A entrevista, sob a ótica do entrevistado, permite uma reformulação de sua identidade, na medida em que ele se vê perante o outro, ou seja, o entrevistado torna-se capaz de se ver como o criador da história, à medida que, de alguma maneira, transformou e transforma o mundo em sua vivência, questionando elementos da vida social. Assim: "Essas pessoas, de objetos de pesquisa, se tornam sujeitos, pois percebem não só sua história de vida, mas seu projeto de vida nesse processo de autoanálise" (LE VEN; FARIA; MOTTA, 1997, p. 220).

Sob a ótica do pesquisador, a entrevista de cunho biográfico torna-se, além de um trabalho analítico, de cunho científico, um trabalho social. Ao tentar compreender os sujeitos com deficiência e transtornos globais do desenvolvimento entrevistados, a partir da história de vida dos mesmos, o pesquisador auxilia o entrevistado a compreender-se enquanto agente de transformação social (LE VEN; FARIA; MOTTA, 1997). De forma ainda mais ampla, a entrevista produz no pesquisador, uma reflexão sobre sua própria vida, já que

[...] Os diferentes pontos de vista, concepções de mundo e modos de atuação proporcionados pelo entrevistado suscitam no entrevistador uma reflexão sobre si mesmo e novos questionamentos sobre sua experiência e projeto de vida. Assim sendo, podemos inferir que os indivíduos não continuam os mesmos após a realização de entrevistas de história de vida (LE VEN; FARIA; MOTTA, 1997, p. 221).

Além disso, nessa proposta,

O roteiro para entrevista semiestruturada não se constituiu em sequência rígida de questionamentos e dados a serem relatados, mas apenas como um roteiro dos itens principais a serem abordados, para a orientação do próprio sujeito (JUNGES, 2005, p. 61).

É de relevância ressaltar que, na entrevista biográfica, não é suficiente apenas o discurso verbal do entrevistado. Existem, ainda, além dos fatores linguísticos do enunciado 
do sujeito, os caracteres extraverbais que devem ser avaliados e sensivelmente percebidos, por parte do pesquisador.

A entoação exerce um papel fundamental na constituição dos sentidos que
envolvem atos de fala e dão forma a eles. É essencialmente sensível a todas as
vibrações do ambiente social que envolve o falante. Daí a importância de o
pesquisador registrar a atmosfera afetiva que envolve as entrefalas e os
entretextos, os não-ditos que estão presentes no gesto, no olhar, na entoação e no
corpo, pois tudo isto é parte integrante do sentido do diálogo (KRAMER; SOUZA,
2008, p. 29).

A entrevista biográfica permite ao pesquisador um rompimento da clausura acadêmica que a transformava em simples suporte documental, em pesquisa social e histórica, propiciando a mesma desvelar a riqueza inesgotável do depoimento, como fonte não apenas informativa, mas, sobretudo, como instrumento de compreensão mais ampla e globalizante do significado da ação humana, de suas relações com a sociedade organizada, com as redes de sociabilidade, com o poder e o contrapoder existentes, e com os processos macroculturais que constituem o ambiente dentro do qual se movem os atores e os personagens desse drama ininterrupto - sempre mal-decifrado - que é a História Humana (ALBERTINI, 1990 apud CASSAB; RUSCHEINSKY, 2004).

\subsection{Histórias de vida de adultos com deficiência}

O olhar das histórias de vida de adultos com deficiência, a partir de uma perspectiva sócio-histórica, pode ser capaz de trazer à tona sentimentos, significações, construções e desconstruções desses sujeitos, que, uma vez internalizados, podem contribuir para o processo de aprendizagem e desenvolvimento humano, como demonstraram estudos de Santos (2013) e Drago (2012). Ao narrar suas trajetórias de vida, esses sujeitos se percebem produtores históricos, culturais e sociais de suas ações? Concebem, de maneira consciente, sua deficiência restrita ao plano biológico e, portanto, não inibidora do desenvolvimento de suas funções psicológicas superiores?

A escolha pela referida metodologia, alicerçada nos moldes sócio-históricos que têm sido a tônica de nossos estudos, se torna compatível à pesquisa com adultos, pois acreditamos que:

A narrativa é tanto um fenômeno quanto uma abordagem de investigação e formação, porque parte das experiências e dos fenômenos humanos advindos das mesmas. O que é a educação senão a construção sócio-histórica e cotidiana das narrativas pessoal e social? O cotidiano humano é, sobremaneira, marcado pela 
troca de experiências, pelas narrativas que ouvimos e que falamos, pelas formas como contamos as histórias vividas (SOUZA, 2007, p. 05).

Nesse sentido, podemos questionar: o que representam as experiências relatadas por esses sujeitos senão o reflexo das mediações vividas em suas trajetórias de vida?

A partir dos relatos das narrativas, é possível inferir que por mais semelhanças que apresentem em suas trajetórias de vida e, portanto, na formação e na sua constituição identitária e subjetiva, cada sujeito constrói sua própria teia nos fios de relações tecidas para com pessoas, lugares, espaços, cultura e sociedade. Tudo depende de como se reconstruíram as operações externas, no interior de cada um, num processo de internalização que precisa ser ouvido e registrado.

Desse modo, a internalização das experiências vividas por cada adulto tem início nos processos sociais desde a infância e, portanto nas relações estabelecidas com pessoas, espaços, lugares, cultura. Em segunda instância, as mediações vivenciadas permitem a tomada de consciência de si e do outro, numa relação dialética e semiótica, demonstrando a importância dos processos socioculturais para o percurso da construção ativa do sujeito que, segundo Cavalcanti (2005, p. 188), "transforma, via internalização, os conteúdos externos em conteúdos da consciência".

Essa internalização, a nosso ver, pode passar por momentos de muito desprazer e desrespeito ao outro como ser que possui peculiaridades muito específicas. Nesse sentido, vale salientar que resgatar a história de vida de sujeitos que viveram/venceram desafios também é uma forma de respeitar suas individualidades, de mostrar à sociedade que pessoas com deficiência galgam caminhos diferentes, possuem características muito peculiares que precisam ser reconhecidas. Assim, para refletirmos, vale destacar uma fala de Sennet (2004, p. 13), quando o autor nos chama a atenção para o modo como enxergamos/percebemos o outro:

É certo que a sociedade tem uma ideia dominante: de que, ao nos tratarmos como iguais, afirmamos o respeito mútuo. Mas será que só podemos respeitar as pessoas que são tão fortes quanto nós? Algumas desigualdades são arbitrárias, mas outras são intratáveis - como as diferenças de talento. Na sociedade moderna, em geral as pessoas não conseguem levar a consideração e o respeito mútuo através dessas fronteiras.

Nesse caminho, abordando o aspecto da deficiência no que se refere à formação e constituição de cada sujeito a partir de sua fala, somos conduzidos a pensar, parafraseando Vigotski (1989), que o processo de compensação e, portanto da superação de uma limitação, 
nem sempre termina em êxito para o sujeito, mas conduz, sempre, para a formação de uma capacidade a partir do defeito. Como qualquer processo de superação e de luta, a compensação também pode ter dois extremos: a vitória e a derrota, entre os quais se situam todos os graus possíveis de transição de um polo a outro. O desenrolar desse processo depende de muitas causas, mas o fundamental é a correlação entre o grau da insuficiência e a riqueza da causa compensatória.

Por fim, cabe-nos destacar que reconhecer a história de vida de pessoas adultas com deficiência, transtornos globais do desenvolvimento ou com altas habilidades/superdotação e compreender que tais narrativas se apresentam

[...] como uma via de conhecimento que enriquece o repertório epistemológico,
metodológico e conceitual dos educadores, terapeutas e outros profissionais da
relação e das transações sociais (como a mediação, por exemplo). Ela enriquece
também nosso repertório de "pessoas comuns", permitindo-nos desenvolver uma
consciência do si individual e coletivo mais sutil (JOSSO, 2007, p. 25, grifos do
autor).

Nesse sentido, por se tratar da metodologia de história de vida, o que aqui nos é relevante é o ponto de vista do sujeito, já que o objetivo desse tipo de estudo (o de histórias de vida) é justamente apreender e compreender a vida do sujeito conforme ela é relatada e interpretada pelo próprio ator.

Assim sendo, segundo Vaz; Mendes; Maués (2001), as narrativas são saberes que possibilitam caracterizar, compreender e representar a experiência humana. O contar histórias introduz e cristaliza significados, criando uma atmosfera de diálogo intersubjetivo (do entrevistado consigo mesmo e até mesmo do entrevistado com o pesquisador), permitindo aos sujeitos negociarem significados em comum.

A partir da ideia explicitada, temos em mente que a nossa interpretação das histórias de vida dos sujeitos com deficiência, transtornos globais do desenvolvimento ou altas habilidades/superdotação é apenas uma dentro da vasta rede de outras conclusões, indagações e interpretações possíveis à proposição de novas/outras maneiras de se propor ações educativas que garantam o acesso dessas pessoas aos bens culturais produzidos pela humanidade, a partir daquilo que viveram, ou seja, pensando para as gerações futuras modos de ressignificar a ação educativa, no sentido de se reverem os conceitos já experienciados por outros sujeitos. 


\section{REFERÊNCIAS}

BARROS, V. A.; SILVA, L. R. A pesquisa em História de Vida. In: GOULART, I. B. (Org.)

Psicologia Organizacional e do Trabalho; teoria, pesquisa e temas correlatos. São Paulo: Casa do Psicólogo, 2002. p. 134-158.

BERTAUX, D. Biography and society. The life history approach in the social sciences. Beverly Hills: Sage publications, 1981.

BOSI, E. As outras testemunhas. In: DIAS, M. O. L. S. Quotidiano e Poder em São Paulo no Século XIX. São Paulo: Brasiliense, 1984. p. 3-6.

BUENO, B. O. O método autobiográfico e os estudos com histórias de vida de professores: a questão da subjetividade. Revista Educação e Pesquisa, São Paulo, v. 28, n. 1, p. 11-30, jan./jun. 2002.

CASSAB; L. A; RUSCHEINSKY, A. Indivíduo e ambiente: a metodologia de pesquisa da História Oral. Revista do Instituto de Ciências Humanas e da Informação, Rio Grande, v.16, n. 1, p. 724, 2004.

CAVALCANTI, L. de S. Cotidiano, mediação pedagógica e formação de conceitos: uma contribuição de Vygotsky ao ensino de geografia. Caderno Cedes, Campinas, v.25, n.66, p. 185-207, maio/ago. 2005. Disponível em: <http://dx.doi.org/10.1590/S010132622005000200004>. Acesso em: 12 dez. 2012.

DRAGO, R. Síndromes: conhecer, planejar e incluir. Rio de Janeiro: Wak Editora, 2012.

FREITAS, M. T. de A. A abordagem sócio-histórica como orientadora da pesquisa qualitativa. Cadernos de Pesquisa, Campinas, n. 116, p. 21-39, jul. 2002.

GONÇALVES, R. de C.; LISBOA, T. K. Sobre o método da história oral em sua modalidade trajetórias de vida. Revista Katálysis, Florianópolis, v. 10, n. esp, p. 83-92, 2007.

GOODSON, I.F. Dar voz ao professor: as histórias de vida dos professores e o seu desenvolvimento profissional. In: NÓVOA, A., (Org.) Vidas de professores. Porto: Porto Ed., 1992. p.12-35. 
JOSSO, M. C. A transformação de si a partir da narração de histórias de vida. Educação, Porto Alegre, v. 63, n. 3, Ano XXX, p. 413-438, set./dez. 2007.

JUNGES, K. S. Trajetórias de vida, constituição profissional e autonomia de professores. 2005. 129f. Dissertação (Mestrado em Educação) - Universidade Estadual de Ponta Grossa, Ponta Grossa, 2005.

KRAMER, S.; SOUZA, S. J. e (Orgs). Histórias de Professores: leitura, escrita e pesquisa em educação. São Paulo: Ática, 2008.

LE VEN, M. M.; FARIA, E. de; MOTTA, M. H. de S. História Oral de vida. O Instante da entrevista. In: VONSIMSON, O.R. de M. (Org.). Os desafios contemporâneos da História Oral. Campinas: Centro de Memória da Unicamp, 1997. p.213-222.

OLIVEIRA, I. M. de. A narrativa como possibilidade de abordagem dos conhecimentos produzidos pelo professor sobre sua prática. In: SEMINÁRIO DE PESQUISA EM EDUCAÇÃO ESPECIAL - TRAJETÓRIAS DE PESQUISA: INSTITUINDO NOVAS TRILHAS E DIÁLOGOS NA PERSPECTIVA DA INCLUSÃO, 2, 2006, Domingos Martins. Anais... Marília: ABPPE, 2006. p. 251-260. Vol. 1.

SANTOS, C. R. Professores com deficiência no município de Vitória: vidas que compõem histórias. 2013. 153f. Dissertação (Mestrado em Educação) - Universidade Federal do Espírito Santo, Vitória, 2013.

SENNET, R. Respeito: a formação do caráter em um mundo desigual. Rio de Janeiro: Record, 2004.

SILVA, A.P.; BARROS, C.R.; NOGUEIRA, M.L.M.; BARROS, V.A. "Conte-me sua história": reflexões sobre o método de História de Vida. Revista do Centro Acadêmico de Psicologia da FAFICH/UFMG, Belo Horizonte, v. 1, n. 1, p. 25-35, 2007.

SOUZA, E. C. de. História de vida e práticas de formação: escrita de si e cotidiano escolar. Boletim o Salto para o Futuro: história de vida e formação de professores. MEC/SEED: março 2007, p. 3 - 14. 
SPINDOLA, T. SANTOS, R. da S. Trabalhando com a história de vida: percalços de uma pesquisa(dora?). Revista da Escola de Enfermagem da USP, São Paulo, v. 37, n. 2, p. 119126, 2003.

THOMPSON, P. A voz do passado - história oral. São Paulo: Paz e Terra, 1992.

VAZ, A.; MENDES, R.; MAUÉS, E. Episódios e narrativas de professores - experiências e perspectivas docentes discutidas a partir de pesquisa sobre conhecimento pedagógico de conteúdo. Reunião Anual da ANPED, 24. Caxambu, 2001.

VIGOTSKI, L. S. Fundamentos de Defectología. Obras Completas, Tomo V. Habana: Editorial Pueblo e Educacion, 1989.

Enviado em Fevereiro/2013

Aprovado em Setembro/2013 